\title{
APC Promoter Hypermethylation as a Prognostic Marker in Breast Cancer Patients
}

\author{
Pensri Saelee $^{1 *}$, Tanett Pongtheerat ${ }^{2}$
}

\begin{abstract}
Background: Adenomatous polyposis coli (APC) promoter hypermethylation implicated in breast cancer development through Wnt signaling pathway, hypermethylation may result in inactivation of APC expression. This study aimed to investigated whether hypermethylation of APC promoter, the aggressive behavior of breast cancer cells, and correlated them with clinicopathological parameters and survival. Methods: Sixty-one fresh tissues of breast tumor were evaluated for APC promoter hypermethylation with methylation-specific PCR techniques (MS-PCR) and APC mRNA expression level analysis by quantitative real-time reverse transcription-PCR. Results: Our results show aberrant APC hypermethylation status was founded in 27 of 61 cases (44\%), and significantly associated with chemotherapy treatment $(\mathrm{OR}=6.9,95 \% \mathrm{CI}=1.5-31.01, \mathrm{P}=0.01)$, distant metastasis $(\mathrm{OR}=5.52,95 \% \mathrm{CI}=1.27-24.08, \mathrm{P}$ $=0.04)$ as well as APC methylated status also associated with shorter overall survival than those without (8.4 and 11.0 years respectively, $\mathrm{P}=0.02$ ). Conclusion: The findings indicated hypermethylation of APC promoter may be used as a useful prognostic biomarker in breast cancer patients.
\end{abstract}

Keywords: Breast cancer- APC hypermethylation-MS-PCR- treatment- distant metastasis

Asian Pac J Cancer Prev, 21 (12), 3627-3632

\section{Introduction}

Breast cancer is the most common malignancy to be found in women. In Thailand, the incidence rate of breast cancer is the highest type of cancers affecting woman about 31.4/100,000 population (Imsamran et al., 2018).

Several genetic alterations are involved in the development of breast cancer. Such as, the cytosines methylation of the $\mathrm{CpG}$ islands located in the promoter region of genes, which may result in a decreased gene expression, or silencing tumor suppressor genes (without altering the genetic code) and is found to occur in many cancers, including breast cancer. (Paluszczak et al., 2006; Lin et al., 2001; Saelee et al., 2014, Jin et al., 2001).

The Adenomatous polyposis coli (APC) gene located on chromosome 5q21-q22 encodes a large multidomain protein, which contains genetic code for 2,843 amino acids, which play a major role in the Wnt signaling pathway, cell cycle regulation, cell differentiation and proliferation (Shen et al., 2016; Han et al., 2018). The APC tumor suppressor gene is involved for familial adenomatous polyposis (FAP) and initiates carcinogenesis for various cancer types (Kinzler et al., 1996; Shen et al., 2016; Han et al., 2018) such as colo-rectal cancer, prostate cancer, gastric cancer and breast cancer (Matthaios et al., 2016; Richiardi et al., 2009; Tsuchiya et al., 2000; Hiltunen et al., 1997; Saelee et al., 2014; Jin et al., 2001).

Thus, we identify the role of APC CpG-island hypermethylation to be a significant factor in Thai breast cancer patients. Sixty-one breast tumor samples, were evaluated by methylation-specific PCR, to detect promoter hypermethylation of the APC gene. Altered APC mRNA expression level were quantified by quantitative real-time reverse transcription-PCR as well. The results of this research may be used to assess the correlation of this gene and the clinicopathological characteristics of breast cancer among Thai women patients and to clarify the appropriate prognostic biomarker for breast cancer.

\section{Materials and Methods}

\section{Tumor samples}

Sixty-one breast tumor and paired normal breast tissues were collected from the National Cancer Institute, Bangkok, Thailand, during the period 2007-2011. This study was approved by the Institutional Review Board (IRB) of the National Cancer Institute, Bangkok, Thailand. Patients who had not received chemotherapy or radiotherapy were recruited into this study. Tissue samples were snap-frozen in liquid nitrogen and kept at $-80^{\circ} \mathrm{C}$ until used. Clinicopathological data such as age at diagnosis, tumor size, histological grade, lymph-node 
status, number of lymph nodes, tumor stage, hormone receptor status and HER2, triple-negative tumor (ER-, PR- and HER2-), chemotherapy treatment (anthracycline and anthracycline+taxane), distant metastasis (bone, lung and liver) and follow-up over 13 years, were collected from medical records.

\section{DNA extraction and sodium bisulfite treatment}

Sixty-one breast tumors were extracted by proteinase $\mathrm{K}$ digestion and salting-out method (Miller et al., 1988). Sodium bisulfite conversion of DNA samples was performed using an EZ DNA Methylation Gold kit (Zymo Research, Orange, CA). One $\mu$ g of extracted DNA was treated with sodium bisulfite, following the manufacturer's instruction manual. The converted DNA was eluted in a total volume of $25 \mu \mathrm{l}$ and stored at $-20{ }^{\circ} \mathrm{C}$ until use.

\section{RNA Isolation and cDNA synthesis}

Fifty-one breast tumors and their corresponding normal breast tissues was extracted for total RNA by using Trizol re-agent, according to the instruction protocol (Invitrogen, Carlsbad, CA, USA). mRNA was purified by Oligotex mRNA purification kit (QIAGEN, Gmbh, Germany) and reverse-transcribed using the iScriptTM Select cDNA Synthesis Kit (Bio-Rad Laboratories, Inc., Hercules, CA) for reverse transcription-polymerase chain reaction (RT-PCR) (Invitrogen, Carlsbad, CA, USA).

\section{Methylation-specific PCR}

The APC methylation status in sixty-one breast tumors was performed by methylation specific-PCR on sodium bisulfite treated DNA. The methylated and unmethylated primers were FM- APC-5'TAT TGC GGA GTG CGG GTC-3'; RM-APC-5'TCG ACG AAC TCC CGA CGA-3'; FU-APC- 5'-GTG TTT TAT TGT GGA GTG TGG GTT-3'; RU-APC-5'-CCA ATC AAC AAA CTC CCAACAA-3' (Esteller et al., 2000). The reactions were conducted in a total volume of $25 \mu$, containing $100 \mathrm{ng}$ of bisulfite-treated DNA, 1X PCR buffer, 0.2 $\mathrm{mM}$ of each dNTP, $2.5 \mathrm{mM} \mathrm{MgCl}, 0.4 \mu \mathrm{M}$ of forward and reverse primers, $0.5 \mathrm{X}$ GC-rich solution and 1 unit of FastStart TaqDNA Polymerase (Roche Diagnostics, Mannheim, Germany). Reaction mixtures were hot-started at $95^{\circ} \mathrm{C}$ for $5 \mathrm{~min}$. Amplification was performed in a Mastercycler gradient (Eppendorf) for 30 cycles (1 min at $95^{\circ} \mathrm{C}, 30 \mathrm{sec}$ at $59^{\circ} \mathrm{C}$ (methylated sequence) and $60^{\circ} \mathrm{C}$ (unmethylated sequence) and $30 \mathrm{sec}$ at $72^{\circ} \mathrm{C}$, followed by a final extension of $5 \mathrm{~min}$ at $72^{\circ} \mathrm{C} .25$ microliters of PCR product were electrophoresed in $1.5 \%$ agarose gel, stained with ethidium bromide, and photographed under UV light (Figure 1.).
APC mRNA expression level analysis by quantitative real-time reverse transcription- $P C R$

Altered APC mRNA expression levels were analyzed by LightCycler Instrument (Roche Applied Science). The reaction mixture was $20 \mathrm{ng}$ of template cDNA, 1x LightCycler FastStart DNA Master SYBR Green I (Roche Applied Science, Germany), $4 \mathrm{mM}$ $\mathrm{MgCl} 2$ and $0.5 \mu \mathrm{M}$ forward and reverse primers in a final volume of $10 \mu \mathrm{l}$. The primer sequences were designed by Primer3 program, forward F-APC (5' - TATCCATGCGACAGTCTGGA-3') and reverse R-APC (5'-CCACTCCCAACAGGTTTC AC-3', $\beta$-globin housekeeping gene was used as an endogenous reference to obtain relative expression values. PCR was started at $95^{\circ} \mathrm{C}$ for $5 \mathrm{~min}$ (to activate the FastStart Taq), followed by 40 -cycle amplification $\left(95^{\circ} \mathrm{C}\right.$ for $10 \mathrm{~s}, 62^{\circ} \mathrm{C}$ for $30 \mathrm{~s}$, and $72^{\circ} \mathrm{C}$ for $\left.30 \mathrm{~s}\right)$. After the PCR, each amplification reaction was checked using a dissociation curve. PCR product purity was checked by $1.5 \%$ agarose gel electrophoresis, stained with ethidium bromide, and photographed under UV light. Relative gene expression values were computed, as previously described by Livak and Schmittgen (2001). The cutoff values for gene expression were adopted from median expression levels. Tumor gene expression $<0.3$-fold was evaluated as reduced-expression for APC.

\section{Statistical analysis}

The association between APC hypermethylation, APC mRNA expression level, and clinicopathological characteristics was examined statistically by a chi-square test, while survival was analyzed for patients who were followed up over 13 years, or until death, after surgery. The Kaplan-Meier method and Log rank test, were used to analyze between APC methylation and unmethylation groups. The Cox regression method was utilized to assess the prognostic effect for aberrant APC gene methylation on breast cancer patient survival. A P value $<0.05$ was considered a significant association.

\section{Results}

\section{Methylation analysis}

Sixty-one breast carcinomas were examined for APC methylation status by methylation-specific PCR. The results found 27 of 61 (44\%) tumor samples were positive for methylation status (Figure 1). A statistically significant correlation was observed between APC hypermethylation and chemotherapy treatment (anthracycline and anthracycline+taxane) $(\mathrm{OR}=6.9,95 \% \mathrm{CI}=1.5-31.01, \mathrm{P}=0.01)$, and distant metastasis $(\mathrm{OR}=5.52,95 \% \mathrm{CI}=1.27-24.08, \mathrm{P}=0.04)$,

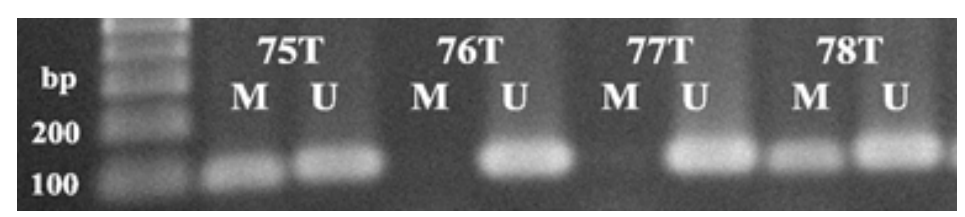

Figure 1. APC Promoter Hypermethylation Status in Breast-Tumor (T) Samples by Methylation-Specific PCR were Detected by Agarose Gel and Visualized by Ethidium Bromide Staining. M, methylated sequence (98 bp); U, unmethylated sequence (108 bp); bp = basepair 
DOI:10.31557/APJCP.2020.21.12.3627

APC Promoter Hypermethylation as a Prognostic Marker in Breast Cancer Patients

Table 1. Association between APC Hypermethylation Status and Clinicopathological Variables in Sixty-One Breast Cancer Patients

\begin{tabular}{|c|c|c|c|c|c|}
\hline \multirow[t]{3}{*}{ Parameter } & \multirow{3}{*}{ No. } & \multicolumn{2}{|c|}{ APC methylation } & \multirow[t]{3}{*}{ Odds ratio, $(95 \% \mathrm{CI})$} & \multirow[t]{3}{*}{$\mathrm{P}$} \\
\hline & & U & $\mathrm{M}$ & & \\
\hline & & $\mathrm{n}(\%)$ & $\mathrm{n}(\%)$ & & \\
\hline Age & & & & $1.79,(0.64-4.96)$ & 0.31 \\
\hline$\leq 50$ & 32 & $20(62.5)$ & $12(37.5)$ & & \\
\hline$>50$ & 29 & $14(48.3)$ & $15(51.7)$ & & \\
\hline Tumor size(cm) & & & & $1.13,(0.45-3.79)$ & 0.79 \\
\hline$\leq 3$ & 37 & $21(56.8)$ & $16(43.2)$ & & \\
\hline$>3$ & 22 & $11(50.0)$ & $11(50.0)$ & & \\
\hline Histologic grade & & & & $2.22,(0.77-6.44)$ & 1.85 \\
\hline $\mathrm{I}+\mathrm{II}$ & 33 & $21(63.6)$ & $12(36.4)$ & & \\
\hline III & 25 & $11(44.0)$ & $14(56.0)$ & & \\
\hline Tumor stage & & & & $1.92,(0.69-5.39)$ & 0.30 \\
\hline I, IIA, IIB & 32 & $20(62.5)$ & $12(37.5)$ & & \\
\hline IIIA, IIIB & 28 & $13(46.4)$ & $15(53.6)$ & & \\
\hline Lymph-node status & & & & $1.87,(0.64-5.45)$ & 0.30 \\
\hline Negative & 23 & $15(65.2)$ & $8(34.8)$ & & \\
\hline Positive & 38 & $19(50.0)$ & $19(50.0)$ & & \\
\hline Lymph nodes (no.) & & & & $2.58,(0.88-7.54)$ & 0.11 \\
\hline $0-3$ positive & 39 & $25(64.1)$ & $14(35.9)$ & & \\
\hline$>3$ positive & 22 & $9(40.9)$ & $13(59.1)$ & & \\
\hline \multicolumn{6}{|l|}{ Immunohistochemical } \\
\hline ER status & & & & $1.54,(0.52-4.58)$ & 0.58 \\
\hline Negative & 21 & $13(61.9)$ & $8(38.1)$ & & \\
\hline Positive $(1+, 2+, 3+)$ & 37 & $19(51.4)$ & $18(48.6)$ & & \\
\hline PgR status & & & & $1.81,(0.63-5.19)$ & 0.30 \\
\hline Negative & 27 & $17(63.0)$ & $10(37)$ & & \\
\hline Positive $(1+, 2+, 3+)$ & 31 & $15(48.4)$ & $16(51.6)$ & & \\
\hline HER2 status & & & & $1.71,(0.45-6.41)$ & 0.51 \\
\hline Negative & 46 & $27(58.7)$ & $19(41.3)$ & & \\
\hline Positive $(1+, 2+, 3+)$ & 11 & $5(45.5)$ & $5(54.5)$ & & \\
\hline Triple negative tumor & & & & $0.39,(0.11-1.33)$ & 0.15 \\
\hline ER,PR,HER2 positive & 39 & $18(46.2)$ & $21(53.8)$ & & \\
\hline ER,PR, HER2 negative & 16 & $11(68.8)$ & $5(31.3)$ & & \\
\hline APC reduced-expression & & & & $0.86,(0.18-4.13)$ & 1.00 \\
\hline No & 39 & $23(59.0)$ & $16(41.0)$ & & \\
\hline Yes & 8 & $5(62.5)$ & $3(37.5)$ & & \\
\hline \multicolumn{6}{|l|}{ Chemotherapy treatment } \\
\hline Antracycline & 33 & $23(69.7)$ & $10(30.3)$ & $6.90,(1.5-31.01)$ & $0.01 *$ \\
\hline Antracycline+Taxane & 12 & $3(25.0)$ & $9(75.0)$ & & \\
\hline \multicolumn{6}{|l|}{ Distant metastasis } \\
\hline No & 43 & $29(67.4)$ & $14(32.6)$ & $5.52,(1.27-24.08)$ & $0.04 *$ \\
\hline Yes & 11 & $3(27.3)$ & $8(72.7)$ & & \\
\hline
\end{tabular}

CI, confidence interval; M, methylated allele; $\mathrm{U}$, unmethylated allele; *, statistically significant correlation

respectively, while there was no association between APC hypermethylation status and APC mRNA reducedexpression as Table 1.
APC mRNA gene expression analysis

This study we also analyzed altered APC mRNA expression level in fifty-one breast tumors and paired normal breast tissues by quantitative real-time reverse transcription-PCR. Our findings show that there was 
Table 2. Association between APC mRNA Reduced-Expression and Clinicopathological Parameters in Fifty-One Breast Cancer Patients

\begin{tabular}{|c|c|c|c|c|c|}
\hline \multirow[b]{2}{*}{ Parameter } & \multirow[t]{2}{*}{ No. } & \multicolumn{2}{|c|}{ APC reduced-expression } & \multirow[t]{2}{*}{ Odds ratio, $(95 \% \mathrm{CI})$} & \multirow[t]{2}{*}{$\mathrm{P}$} \\
\hline & & $\begin{array}{l}\text { APC- } \\
\text { n }(\%)\end{array}$ & $\begin{array}{l}\mathrm{APC}+ \\
\mathrm{n}(\%)\end{array}$ & & \\
\hline Age & & & & $1.05,(0.23-4.74)$ & 1.00 \\
\hline$\leq 50$ & 26 & $22(84.6)$ & $4(15.4)$ & & \\
\hline$>50$ & 25 & $21(84.0)$ & $4(16.0)$ & & \\
\hline Tumor size(cm) & & & & $0.25,(0.03-2.22)$ & 0.24 \\
\hline$\leq 3$ & 31 & $25(80.6)$ & $6(19.4)$ & & \\
\hline$>3$ & 18 & $17(94.4)$ & $1(5.6)$ & & \\
\hline Histologic grade & & & & $1.02,(0.20-5.14)$ & 1.00 \\
\hline $\mathrm{I}+\mathrm{II}$ & 27 & $23(85.2)$ & $4(14.8)$ & & \\
\hline III & 20 & $17(85.0)$ & $3(15.0)$ & & \\
\hline Tumor stage & & & & $1.28,(0.28-5.83)$ & 1.00 \\
\hline I, IIA, IIB & 27 & $23(85.2)$ & $4(14.8)$ & & \\
\hline IIIA, IIIB & 22 & $18(81.8)$ & $4(18.2)$ & & \\
\hline Lymph-node status & & & & $0.98,(0.21-4.70)$ & 1.00 \\
\hline Negative & 19 & $16(84.2)$ & $3(15.8)$ & & \\
\hline Positive & 32 & $27(84.4)$ & $5(15.6)$ & & \\
\hline Lymph nodes (no.) & & & & $0.56,(0.10-3.13)$ & 0.70 \\
\hline 0-3 positive & 33 & $27(81.8)$ & $6(18.2)$ & & \\
\hline$>3$ positive & 18 & $16(88.9)$ & $2(11.1)$ & & \\
\hline \multicolumn{6}{|l|}{ Immunohistochemical } \\
\hline ER status & & & & $0.34,(0.07-1.72)$ & 0.23 \\
\hline Negative & 17 & $13(76.5)$ & $4(23.5)$ & & \\
\hline Positive $(1+, 2+, 3+)$ & 32 & $29(90.6)$ & $3(9.40)$ & & \\
\hline PgR status & & & & $0.56,(0.11-2.83)$ & 0.68 \\
\hline Negative & 22 & $18(81.8)$ & $4(18.2)$ & & \\
\hline Positive $(1+, 2+, 3+)$ & 27 & $24(88.9)$ & $3(11.1)$ & & \\
\hline HER2 status & & & & $1.71,(0.45-6.41)$ & 0.57 \\
\hline Negative & 41 & $34(82.9)$ & $7(17.1)$ & & \\
\hline Positive $(1+, 2+, 3+)$ & 7 & $7(100)$ & 0 & & \\
\hline Triple negative tumor & & & & $6.00,(0.95-37.86)$ & 0.06 \\
\hline ER,PR,HER2 positive & 32 & $30(93.8)$ & $2(6.3)$ & & \\
\hline ER,PR, HER2 negative & 14 & $10(71.4)$ & $4(28.6)$ & & \\
\hline Chemotherapy treatment & & & & $2.80,(0.03-2.71)$ & 0.38 \\
\hline Antracycline & 5 & $17(73.9)$ & $6(26.1)$ & & \\
\hline Antracycline+Taxane & 31 & $10(90.9)$ & $1(9.1)$ & & \\
\hline \multicolumn{6}{|l|}{ Distant metastasis } \\
\hline No & 35 & $29(82.9)$ & $6(17.1)$ & $5.52,(1.27-24.08)$ & 1.00 \\
\hline Yes & 9 & $8(88.9)$ & $1(11.1)$ & & \\
\hline
\end{tabular}

CI, confidence interval; -, no reduced-expression; +, reduced-expression

no association between APC mRNA expression and clinicopathological parameters including survival as shown in Table 2.

\section{Survival of breast cancer patients}

Overall survival analysis was determined by the Kaplan-Meier survival curve and the Log rank test was used to compare the survival time between methylated and unmethylated patients. The data summarizes significant correlation between APC methylated and survival. The breast cancer patients were found APC methylated of promoter region reduced the survival period than APC unmethylated status (8.4 and 11.0 years respectively, $\mathrm{P}=0.02$, Figure 2). Furthermore, Multivariate Cox regression analysis revealed APC hypermethylation was an independent prognostic factor that affect breast cancer survival $(\mathrm{HR}=3.57,95 \% \mathrm{CI}=1.27-10.01, \mathrm{P}=0.016)$, see Table 3). 
DOI:10.31557/APJCP.2020.21.12.3627

APC Promoter Hypermethylation as a Prognostic Marker in Breast Cancer Patients

Table 3. Multivariate Cox Regression Method of Prognostic Biomarkers for Survival of Breast Cancer Patients

\begin{tabular}{lccc}
\hline Parameter & HR & $95 \%$ CI & P \\
\hline Tumor size (cm); $>3$ vs $\leq 3$ & 1.33 & $0.47-3.75$ & 0.59 \\
Lymph nodes (no.); >3 vs $\leq 3$ & 1.87 & $0.44-7.92$ & 0.40 \\
Tumor stage; IIIA, IIIB vs I, IIA, IIB & 1.64 & $0.39-6.81$ & 0.50 \\
APC methylation status; methylated allele vs unmethylated allele & 3.57 & $1.27-10.01$ & $0.016^{*}$ \\
APC reduced-expression; positive vs negative & 0.75 & $0.13-4.55$ & 0.76 \\
\hline
\end{tabular}

HR, hazard ratios; CI, confidence interval; *, statistically significant correlation

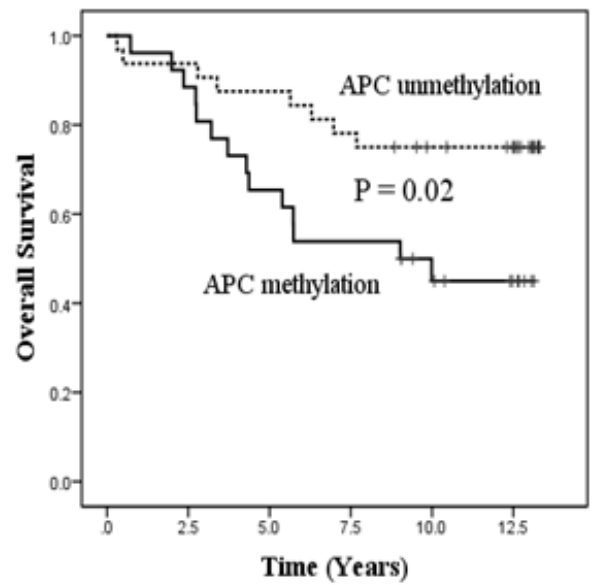

Figure 2. Kaplan-Meier Analysis for Overall Survival of Breast Cancer Patients and Log Rank Test was Used to Compare between APC Methylation and Those without $(\mathrm{P}=0.02)$.

\section{Discussion}

Several studies have reported that APC promoter hypermethylation are involved in carcinogenesis (Esteller et al., 2000; Han et al., 2018). Especially in breast cancer, It has been indicated that the reduction of APC gene expression is induced by CpG-island hypermethylation, observed in up to $70 \%$ of breast cancers (Stefanski et al., 2019). In the present study, we observed the frequency of APC CpG-island hypermethylation of breast-cancer samples, and found that $44 \%$ of patients showed promoter hypermethylation.

This study, APC hypermethylation was found to be significantly associated with a group of patients who received adjuvant anthracycline plus taxane-based chemotherpy ( $\mathrm{P}=0.01)$. Recently, DNA methylation have demonstrated as a potential biomarker for decision-making in the treatment of cancer patients (Duffy et al., 2009; Stefansson et al., 2013). However, this is the first research for demonstrating APC methylation status correlated with chemotherapy treatment in breast cancer. Indicating that determination of the APC promoter hypermethylation status may serve as a predictive marker for therapy monitoring and prediction of therapy response in breast cancer patients.

Furthermore, our analysis also show that APC methylation was related to metastasis breast cancer case $(\mathrm{P}=0.04)$. In accordance with previous report of Debouki-Joudi et al., (2014) demonstrated aberrant methylation of APC was associated with distant metastasis
$(\mathrm{P}=0.031)$ in familial breast cancer. Chen et al., (2005) revealed that APC promoter hypermethylation was found in CRC hepatic metastasis. Moreover, hypermethylation of Cyclin D2, RAR-beta, Twist, RASSF1A, and HIN-1 genes was significantly increase in distant metastases compared with their primary site of breast cancer (Mehrotra et al., 2004). This suggested APC methylation may be involved with a biologically aggressive phenotype and play a role in a progression among breast-cancer patients. Two major mechanisms that contributed to metastasis, one is APC methylation frequenly occurs early in breast cancer and increases during disease progression and the other one is that 'de novo' occur in the metastatic cancer cells even in lacking of methylation in the primary cancer cells (Chen et al., 2005). This information that may be important to the biology of distant metastasis and that may assist in the design of therapeutic modalities (Mehrotra et al., 2004).

We also studied APC mRNA expression and results showed that there was no association between APC promoter hypermethylation and APC reduced-expression. That correlated with previous reports such as Van der Auwera et al., (2008) who reported, there was no significant correlation between APC methylation and APC mRNA or protein expression levels in breast cancer phenotypes as well as in colo-rectal cancer metastasis. Lacking the correlation between APC methylation and APC reduced-expression could be possible due to the fact that only one allele was methylated, allowing expression from the unmethylated allele (Chen et al., 2005). Therefore, hypermethylation was not the sole mechanism that affected APC expression in breast cancer. Several mechanisms affect APC expression in breast cancer (Turker et al., 2002). Such as gene mutations or allelic losses that may affect APC gene expression (Van der Auwera et al., 2008).

Moreover, our data showed that loss of APC function from promoter methylation status is trends to be aggressive behavior of cancer cell. Recently, Univariate analysis of Kaplan Meier analyses was used to evaluated the correlations between APC methylated status and patient's survival times. Our results suggested breast cancer patients who had APC hypermethylation status shown a wores prognosis when comparing with unmethylated group ( $\mathrm{P}=0.02)$. Additionally, Multivaritae analysis by Cox regesion model was utilize to estimate which the prognostic variables may affect survival of breast cancer patients. Analyses were adjusted for tumor size, number of lymph nodes, tumor stage, APC reduced-expression and APC methylation status, the findings revealed APC methylation status shown as an independent prognostic 
factor that affect survival $(\mathrm{HR}=3.57,95 \% \mathrm{CI}=1.27-10.01$, $\mathrm{P}=0.016)$. This study indicating that APC methylation status is a risk variable that affect on survival of breast cancer patients. Sevral previous studies suggested APC methylation was associated with survival of breast cancer in Tunisian patients $(\mathrm{p}=0.046)$ (Debouki-Joudi et al., 2017). DNA methylation of APC in serum of early breast cancer patients who had not undergone adjuvant systemic treatment appeared to be an independent prognostic marker for overall survival (Muller et al., 2003). The tumor suppressor APC in breast cancer, methylation frequency has been correlated with a poor prognosis (Virmani et al., 2001; Sarrio et al., 2003). APC hypermethylation of high to moderate differentiation prostate cancer patients was shown associated with poor survival and patients with an unmethylated APC gene had better survival in metastatic CRC (Richiardi et al., 2009; Matthaios et al., 2016).

In conclusion, it was found that $44 \%$ of Thai breast cancers had APC promoter hypermethylation. This hypermethylation is associated with chemotherapy treatment, distant metastasis and overall survival of patients. The APC promoter hypermethylation is an aggressive biological phenotype in breast cancer and may be used as a worse case prognosis in breast cancer patients.

\section{Acknowledgements}

This work was supported by a grant from the Fiscal Budget of the Royal Thai Government.

\section{Conflicts of interest}

None to declare.

\section{References}

Chen J, Röcken C, Lofton-Day C, et al (2005). Molecular analysis of APC promoter methylation and protein expression in colorectal cancer metastasis. Carcinogenesis, 26, 37-43.

Debouki-Joudi S, Trifa F, Khabir A, et al (2017). CpG methylation of APC promoter 1A in sporadic and familial breast cancer patients. Cancer Biomark, 18, 133-41.

Duffy MJ, Napieralski R, Martens JWM, et al (2009). Methylated genes as new cancer biomarkers. Eur J Cancer, 45, 335-46.

Esteller M, Sparks A, Toyota M, et al (2000). Analysis of adenomatous polyposis coli promoter hypermethylation in human cancer. Cancer Res, 60, 4366-71.

Han W, Wang Y, Fan J, et al (2018). Is APC hypermethylation a diagnostic biomarker for bladder cancer? A meta-analysis. Onco Targets Ther, 11, 8359-69.

Hiltunen MO, Alhonen L, Koistinaho J, et al (1997). Hypermethylation of the APC (adenomatous polyposis coli) gene promoter region in human colorectal carcinoma. Int $J$ Cancer, 70, 644-8.

Imsamran W, Pattatang A, Supaattgorn P, et al (2018). Cancer in Thailand, Vol. IX, 9

Jin Z, Tamura G, Tsuchiya T, et al (2001) Adenomatous polyposis coli (APC) gene promoter hypermethylation in primary breast cancers. Br J Cancer, 85, 69-73.

King TD, Suto MJ, Li Y (2012). The Wnt/ $\beta$-catenin signaling pathway: a potential therapeutic target in the treatment of triple negative breast cancer. $J$ Cell Biochem, 113, 13-8.

Kinzler KW, Vogelstein B (1996). Lessons from hereditary colorectal cancer. Cell Oct, 87, 159-70.
Lin IG, Hsieh CL (2001). Chromosomal DNA demethylation specified by protein binding. EMBO Rep, 2, 108-12.

Livak KJ, Schmittgen TD (2001). Analysis of relative gene expression data using real-time quantitative PCR and the 2(-Delta Delta C(T)) Method. Methods, 25, 402-8.

Matthaios D, Balgkouranidou I, Karayiannakis A, et al (2016). Methylation status of the APC and RASSF1A promoter in cell-free circulating DNA and its prognostic role in patients with colorectal cancer. Oncol Lett, 12, 748-56.

Mehrotra J, Vali M, McVeigh M, et al (2004). Very high frequency of hypermethylated genes in breast cancer metastasis to the Bone, Brain, and Lung. Clin Cancer Res, 10, 3104-9.

Miller SA, Dykes DD, Polesky HF (1988). A simple salting out procedure for extracting DNA from human nucleated cells. Nucleic Acids Res, 16, 1215.

Müller HM, Widschwendter A, Fiegl H, Ivarsson L, et al (2003). DNA methylation in serum of breast cancer patients: an independent prognostic marker. Cancer Res, 63, 7641-5.

Paluszczak J, Baer-Dubowska W (2006). Epigenetic diagnostics of cancer--the application of DNA methylation markers. J Appl Genet, 47, 365-75.

Richiardi L, Fiano V, Vizzini L, et al (2009). Promoter methylation in APC, RUNX3, and GSTP1 and mortality in prostate cancer patients. $J$ Clin Oncol, 27, 3161-8.

Saelee P, Chaiwerawattana A, Ogawa K, et al (2014). Clinicopathological significance of BRCA1 promoter hypermethylation in Thai breast cancer patients. Asian Pac J Cancer Prev, 15, 10585-9.

Sarrió D, Moreno-Bueno G, Hardisson D, et al (2003). Epigenetic and genetic alterations of APC and CDH1 genes in lobular breast cancer: relationships with abnormal E-cadherin and catenin expression and microsatellite instability. Int $J$ Cancer, 106, 208-15.

Shen C, Sheng Q, Zhang X, et al (2016). Hypermethylated APC in serous carcinoma based on a meta-analysis of ovarian cancer. J Ovarian Res, 9, 60.

Stefanski CD, Keffler K, McClintock S, et al (2019). APC loss affects DNA damage repair causing doxorubicin resistance in breast cancer cells. Neoplasia, 21, 1143-50.

Stefansson OA, Esteller M (2013) Epigenetic modifications in breast cancer and their role in personalized medicine. $\mathrm{Am} \mathrm{J}$ Pathol, 183, 1052-63.

Tsuchiya T, Tamura G, Sato K, et al (2000). Distinct methylation patterns of two APC gene promoters in normal and cancerous gastric epithelia. Oncogene, 19, 3642-6.

Turker MS (2002). Gene silencing in mammalian cells and the spread of DNA methylation. Oncogene, 21, 5388-93.

Van der Auwera I, Van Laere SJ, Van den Bosch SM, et al (2008). Aberrant methylation of the Adenomatous Polyposis Coli (APC) gene promoter is associated with the inflammatory breast cancer phenotype. Br J Cancer, 99, 1735-42.

VanKlompenberg MK, Bedalov CO, Soto KF, et al (2015). APC selectively mediates response to chemotherapeutic agents in breast cancer. BMC Cancer, 15, 457.

Virmani AK, Rathi A, Sathyanarayana UG, et al (2001). Aberrant methylation of the adenomatous polyposis coli (APC) gene promoter 1A in breast and lung carcinomas. Clin Cancer Res, 7, 1998-2004.

\section{This work is licensed under a Creative Commons Attribution-} Non Commercial 4.0 International License. 